\title{
A technological study of Hassuna culture ceramics (Yarim Tepe I settlement)
}

\author{
Natalia Yu. Petrova \\ State Historical museum, Moscow, RU \\ petrovanatalya7@mail.ru
}

\begin{abstract}
The article presents the results of a comparative technological analysis of Hassuna culture pottery from Yarim Tepe I (6 th millennium BC) from the lower and middle horizons. The technological stages of selecting the clay and organic materials, the composition of the clay paste and the surface treatment, but also certain issues related to the ornamentation and firing of the pottery are presented in the article.
\end{abstract}

IZVLEČEK - Članek predstavlja rezultate primerjalne tehnološke analize lončenine kulture Hassuna iz spodnjih in srednjih horizontov najdišč Yarim Tepe I (6. tisočletje pr. $n$. št.). V članku predstavljamo tehnološke stopnje, ki vključujejo izbor gline in organskih primesi, izdelavo lončarske mase ter obdelavo površine, pa tudi okraševanje in žganje lončenine.

KEY WORDS - Mesopotamia; Hassuna culture; pottery technology; animal dung-temper

\section{Introduction}

Yarim Tepe I is a settlement of the Hassuna culture (6th millennium BC) located in the Sinjar valley some $7 \mathrm{~km}$ south-west from the town of Tell-Afar in Northern Iraq. The settlement was investigated between 1969 and 1976 by the Soviet archaeological expedition of the Institute of Archaeology to the Near East under the leadership of Rauf M. Munchaev and Nikolai Ya. Merpert. Excavations in the $6 \mathrm{~m}$ thick cultural layer identified 12 construction horizons, reflecting all of the stages in the development of Hassuna culture (Munchaev, Merpert 1981.18-155; Merpert 1993). The culture spread through the region of Northern Mesopotamia from the Tigris basin and Hatra district in the east and southeast, to the River Khabur in the west. All stages in the development of Hassuna culture are represented within the territory of the Sinjar Valley (Elias 2003.9). Hassuna pottery was first identified by M. Mallowan during excavations at the Acropolis of Nineveh (Tell Kujundjik) in 1931. The material was present in the layer near the bedrock and named 'Ninevien I' in accordance with the archaeological periodization of the site.
In 1943, S. Lloyd and F. Safar began a study of the multi-layered settlement tell Hassuna, located about $30 \mathrm{~km}$ south of the city of Mosul and $12 \mathrm{~km}$ west of the Tigris River. The finds were associated with the more complete and coherent cultural sequence from which their name derives. Just over $5 \mathrm{~m}$ of cultural deposits were identified in the excavated area of the settlement.

The excavators drew upon diverse and extensive information about much older (and at that time more well-known) Pottery Neolithic in Northern Mesopotamia and proposed a division of the cultural layer into two stages: standard and archaic Hassuna (defined on the basis of pottery morphology and decoration) (Lloyd, Safar 1945).

The excavations of the Soviet archaeological expedition of the Institute of Archaeology at Yarim Tepe I were a significant and important stage in the study of Hassuna culture. The results obtained by the expedition confirmed the division of the Hassuna culture settlements of Eastern Jezirah into the standard 
and archaic stages, but also provided new insights into the existing data and enabled a deeper understanding of the culture's historical development. As at other sites in the Near East and elsewhere, ceramics account for the vast majority of the excavated material from Yarim Tepe I. Although these finds have been studied only typologically in the past, they are now being subjected to arhaeometrical studies at the Institute of Archaeology in Moscow in a comparative study of some technological features of the pottery of the archaic Hassuna and the transition to standard Hassuna at Yarim Tepe I. The ceramic samples consist of fragments of 50 vessels: 25 from the lowest construction horizon of the site (XII) and 25 from the horizon marking the transition to standard Hassuna (VII) (Munchaev, Merpert 1981.90). The vessel assemblage is comprised of a range of formal types, such as bowls (22), jugs (5), jars (14), basins (8) and storage vessels (Fig. 1). These were defined in accordance with the formal classification system proposed by Munchaev and Merpert (1981).

The study of the ceramic material was conducted in accordance with a methodology developed by Alexander A. Bobrinsky (1978). The following steps of the technological process were investigated in this study: the selection of raw materials (step 1), processing of raw materials (step 3), preparation of pottery paste (step 4), surface treatment (step 8), pottery decoration (step 12), and firing (step 9).

In the study of clay selection, the degree of ferrugination of the clay, degree of plasticity and composition of natural inclusions were determined. When considering organic temper, these were classified ac- cording to their type and methods of processing. The study of pottery paste determined the character and concentration of the temper. In addition, the surface treatment of the vessels and types of decoration were investigated. In the study of firing, the approximate temperature and duration was established. Direct analyses of ceramics included: re-firing of samples in a muffle furnace under identical conditions to determine the relative degree of ferrugination of the clay; examining the vessels fragments under a stereo microscope (MBS-10); conducting special experiments to provide data on the composition of organic materials originally present in the pottery paste (Petrova 2011; 2012).

\section{Analysis of raw materials}

The clay served as the main raw material for pottery production and was used in a dry condition. Seven types of clay deposits were identified in the examined material, varying in their degree of plasticity and ferrugination, and in the concentration of natural limestone inclusions (Fig. 2).

In horizon XII (archaic Hassuna) three types of clays were used (the degree of clay plasticity was determined according to data published in Lopatina, Kazdym 2010.47, 52):

(1) Clay with a moderate degree of ferrugination and high-plasticity with fine-medium round natural sand $(0.1-0.25$ and $0.25-0.5 \mathrm{~mm})$, white and light grey, and with small amounts of fine or a combination of fine and coarse limestone inclusions (rounded, light grey/white and friable).
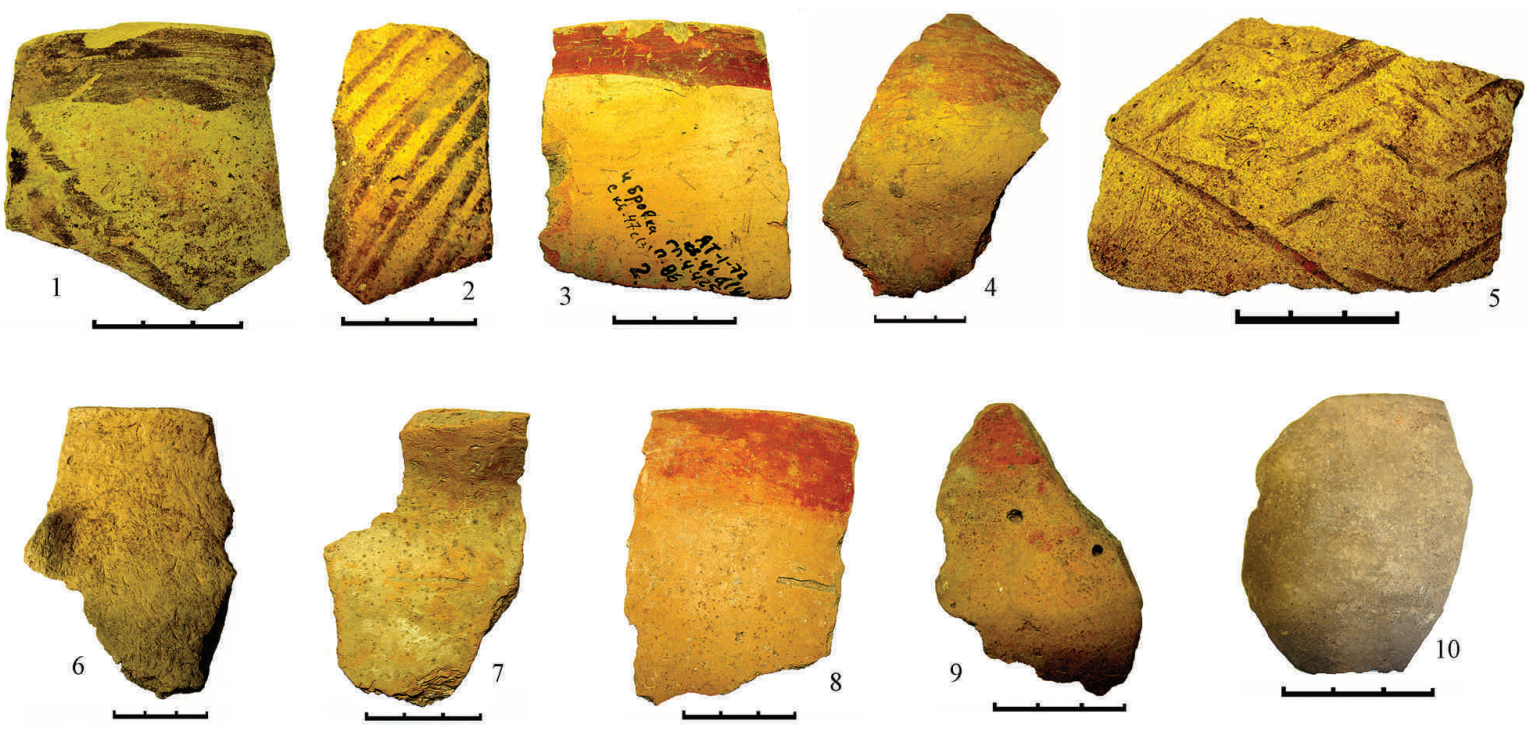

Fig. 1. The analyzed pottery fragments from Yarim Tepe I. 1-5 horizon VII; 6-10 horizon XII. 
(2) Clay with a moderate degree of ferrugination and high plasticity with a large quantity of fine limestone inclusions.

3 Clay with moderate degree of ferrugination and moderate plasticity (with a small amount of fine and medium rounded quartz sand, 0.1- 0.25 and $0.25-0.5 \mathrm{~mm}$ ), white/light grey colours in concentrations of no more than 1:5 and high concentrations of fine limestone inclusions.

It is important to emphasise that in accordance with Bobrinsky's (1999. 25-26) approach the features of the clay resources described above allow
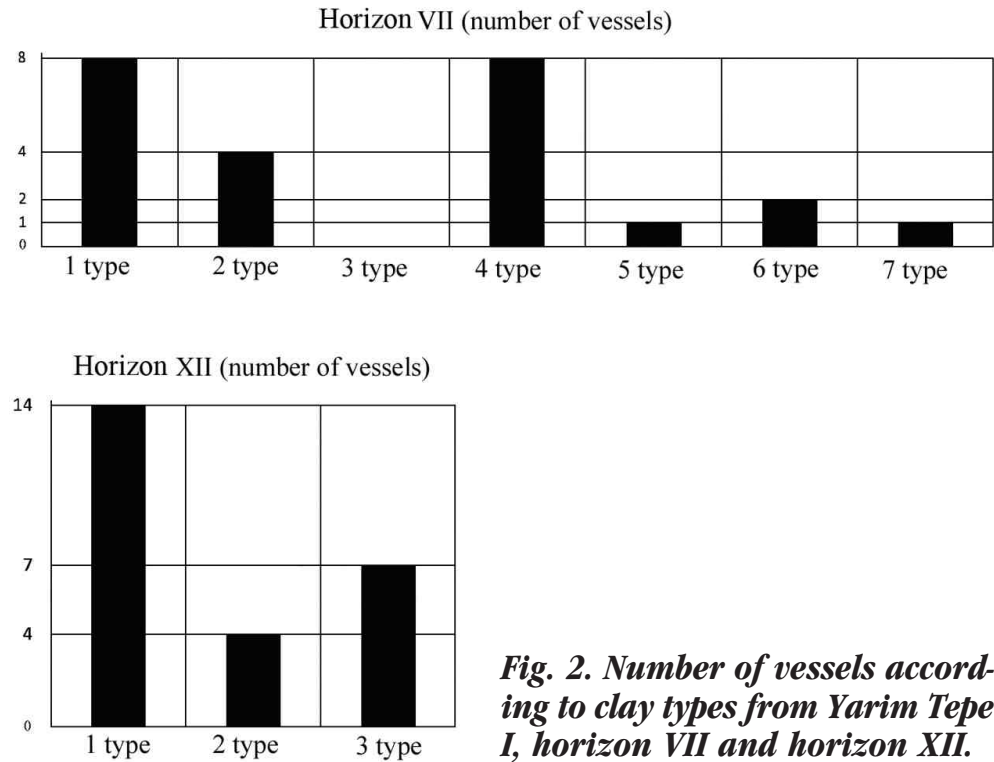

Fig. 2. Number of vessels according to clay types from Yarim Tepe I, horizon VII and horizon XII.

us to conclude that local potters collected clay for pottery within one of the areas, but exploited various clay deposits.

The first type of clay was used most commonly for the manufacture of bowls and basins (29\%), and jars and jugs (21\%). The other types of clay had more specific formal distributions. The second was used predominantly for the manufacture of bowls (75\%), and the third for the production of jars (71\%).

The first type of clay, as described above, was used continuously by local potters through the transition to standard Hassuna (Horizon VII). The second type was also identified, but with some differences in the mineralogical composition (some fragments were seen to contain red sand in addition to the white and light grey inclusions). Again, this type was used solely for making bowls. The third type of clay was not identified.

Alongside the old clay deposits, it was possible to identify the exploitation of new kinds of resources at this time, a number of which were characterised by weakly ferruginated base clay. In total, a further four types of clays were identified in the analysis:

(4) Weakly ferruginated clay with high plasticity, containing a small quantity of fine or a combination of fine and coarse limestone inclusions.

5 A mixture of weakly ferruginated clay with high plasticity and crushed, dry, moderately ferruginated clay. This fact reflects the beginning of the mixing processes of bearers of different pottery traditions. In this clay, a small quantity of fine or a combina- tion of fine and coarse limestone inclusions was also present.

(6 Moderately ferruginated clay with moderate plasticity (with a large quantity of small limestone inclusions), distinguished from the third type by the presence of inclusions of sandstone and individual grains of sand (these were represented as conglomerates consisting of particles of different colours white, grey, red).

0 Weakly ferruginated and high plasticity clay with sandstone inclusions (including conglomerates) and a large quantity of small limestone inclusions.

In this horizon (VII), the fourth type of clay was used for the manufacture of a range of vessels types: bowls (63\%), jars (12\%) and jugs (25\%). In the lowest horizon (XII) only the first kind of clay was used. The fourth type of clay was probably local to the site. The three last types of clay are found only in the manufacture of bowls. The sixth and seventh types, containing sandy conglomerates, were considered significantly different from the local natural types.

Thus, in the analysis of skills in the selection of raw materials, we can come to the following conclusions. First, the use of different types of clay and clay deposits, both in the archaic Hassuna period and through the transition to standard Hassuna, suggests that several potters or groups of potters were working within the settlement. Secondly, we can conclude that the first four types of clay, used in the production of $85 \%$ of the vessels found at the site, were probably of local origin. As will be shown below, they were made in most cases with traditional methods of paste pre- 
paration and decoration. Thirdly, the last three types of clay are probably not local to the site. Vessels made of these clay fabrics are in the minority (they present only $8 \%$ of the total sample) and differ both compositionally and in their method of decoration. The clays of the sixth and seventh types, judging by the presence of natural sandstone inclusions, probably originated in the foothills near the archaeological site. This suggests that a population with a new pottery tradition appeared in the settlement in the transition to standard Hassuna.

\section{Analysis of paste preparation traditions}

Most of the investigated vessels contained organic temper (e.g., plants) but it was difficult to identify them as there are no sufficient analysis of organic temper in pottery available. Bobrinsky paid considerable attention to elucidating the nature of different organic tempers in ceramics, specifying a number of characteristic features which can help determine the nature of such material (Bobrinsky 1978; 1981a; 1981b; 1989; 1999). These studies were continued by Yuri B. Tsetlin (1993; 1999; 2003), Irina N. Vasilyeva (Bobrinsky, Vasilyeva 1998) and Natalia P. Salugina, who presented data from an unpublished experiment dealing with the study of organic remains from animal dung.

However, despite being repeatedly analysed the problem of appearance and identification of organic temper in prehistoric pottery remains unresolved.

As part of the identification of organics in pottery from Yarim Tepe I, a series of experiments was carried out with different types of organic temper containing the following plant residues: fresh grass, hay, straw, and the dung of large (cattle) and small (sheep and goats) livestock (both in dry and humid states). Two sets of experimental samples were made from levigated clay - dried, crushed and finely sieved - with one or more of the organic materials listed above (in total, 20 combinations were analysed). The first set was used to form small vessels, while the second was used to make flat clay plates with prints on their surface. Both sets were fired in an oxidising atmosphere in a muffle furnace at two temperature ranges: up to $300^{\circ} \mathrm{C}$ and $800^{\circ} \mathrm{C}$. A set of conclusions could be drawn from comparative microscopic and trace analyses of the experimental samples with the finds from Yarim Tepe I.

It was found that the pottery from Yarim Tepe I could be divided into two groups (Fig. 3). The first was made from a mixture of clay and dry dung (presumably from small ruminants) and coarse plant temper. In this regard, it is necessary to note that sheep and goat bones prevailed in the osteological assemblages from Yarim Tepe I (Munchaev, Merpert 1981.149). The presence of dung in the paste was identified by the following attributes: (i) the appearance of very small plant residues of up to $0.5 \mathrm{~mm}$ long and $0.1-0.2 \mathrm{~mm}$ wide with smooth, rounded edges; (ii) the appearance of a split along the grain particles of leaf plates and stem $1-5 \mathrm{~mm}$ long and $0.2-1.5 \mathrm{~mm}$ wide (corresponding to groups of plant residues Nos. 1, 2 and 4 as described by Bobrinsky 1999.18). Both these types are associated with plant residues that have passed through the gut of herbivorous animals. Marked crop residues predominate in the first type of temper, which included the dung of small livestock, which is extremely rare in the dung of large livestock. In addition, in some cases round cream-colored pieces that were not present in the natural clay were recorded; this is associated with specific secretions present in the animal dung (Bobrinsky 1999.19). The addition of dung to the paste strengthens the resulting pottery.

All the experimental samples in our study that were tempered with hay, straw and grass were not robust irrespective of the firing temperature and had numerous cracks and therefore broke easily. On the other hand, the samples tempered with dung from either large or small livestock exhibited considerable mechanical strength even at low concentrations. Bobrinsky repeatedly drew attention to the fact that the addition of organic temper (especially from poultry litter and the dung of small ruminants) leads to a stone-like state and considerably strengthens the clay even after drying in the air. The use of animal dung in the past also reduced the amount of shrinkage during drying and firing (Bobrinsky 1999.86-87). The second group contained very little plant remains in small concentrations.

The first group was dominant in the ceramics of the archaic Hassuna horizon (XII) and was identified in 23 vessels (or 92\%). The concentration of dung in the paste is very significant, ranging from $20 \%$ to $40 \%$ of its total volume, while the concentration of coarse plant residues in some cases is approximately $40 \%$. Regarding the degree of humidity, this coarse plant material could be identified as hay, dried or fresh grass, so it is possible that dry conditions prevailed in the archaic Hassuna horizon. The coarse plant material was probably already present in the dung when it was collected. These types of artificial 


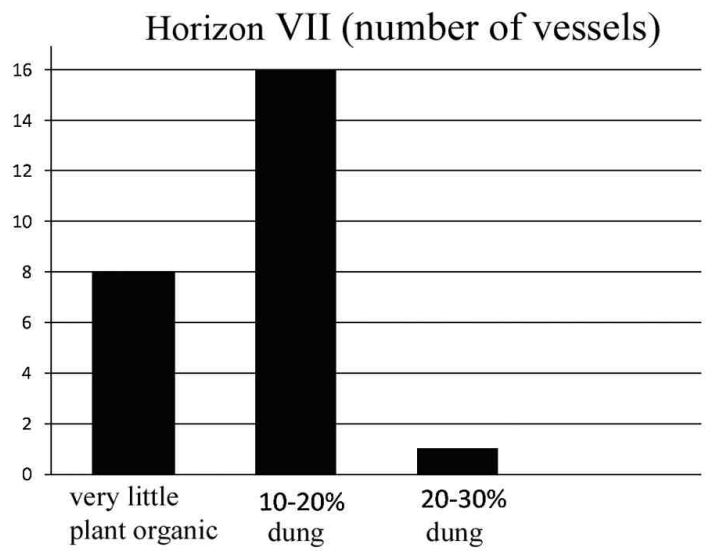

Horizon XII (number of vessels)

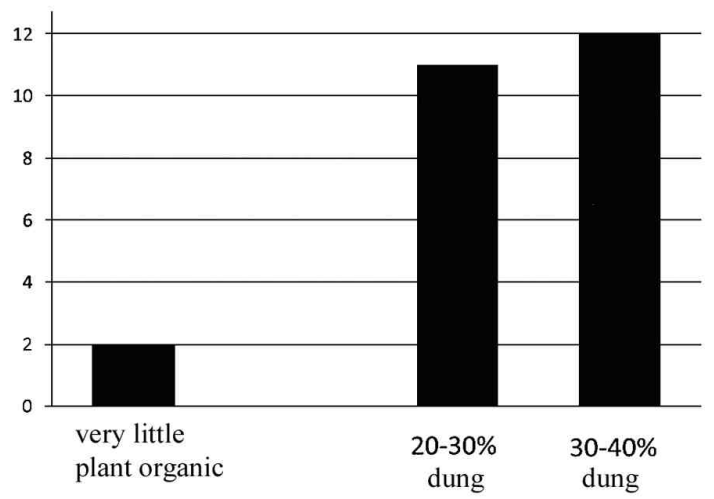

Fig. 3. Number of vessels according to the pottery pastes from Yarim Tepe I, horizon VII and horizon XII.

temper were identified in various forms in both fine and coarse pottery with no clear association with any particular vessel types. Only two thin-walled cups from horizon XII fell into the second group with small and rare plant residues in the paste.

This situation changed significantly during the transition from archaic to standard Hassuna. In horizon VII, 17 vessels of different shapes (68\%) belong to the first organic-tempered group. However, they contain a much lower concentration of dry dung from small livestock, typically around $10 \%$ or less (the percentage can be higher in rare cases, ranging from $20-30 \%)$. The concentration of dry grass residues no longer appears to be a random association with the dung and varies according to the type of vessel: $10-20 \%$ in thin-walled products (jars and bowls) and $20-40 \%$ in more coarse items (thicker-walled vessels such as jars and pans). The dry plant residues in the paste were also different from those recorded in ceramics from the lower layer of the site, being much more consistent in form. The residues typically end and, where it was possible to determine their size, they were between $10-17 \mathrm{~mm}$ long and $1-2 \mathrm{~mm}$ wide. Further research is required to determine whether the form of these plant residues were the result of some special processing technique and were added consciously to the paste or were accompanied by the dung and its treatment. Plant stems cuts were encountered in the experimental samples, where the cut hay (or straw) was added to the paste, but it is difficult to prove that prehistoric potters used similar processing techniques. Nevertheless, it is important to emphasise that this composition of pottery paste was recorded in all of the pottery types that we studied. The second group, in which the paste contained little or no plant material, consisted of eight vessels (or 32\%), all of which were thin-walled bowls. Thus, it may be noted that the transition from archaic to standard Hassuna was characterised by a significant change in the paste preparation by local potters. Although the old technology continued, it was much less used. The spread of new technology can be seen in the use of finer paste, which accounts for a significant share of the assemblage.

This trend is even more evident if the materials from Yarim Tepe I are compared with the materials from the earlier sites in the Sindjar Valley, previously studied by Bobrinsky. Older pottery from proto-Hassuna sites (Tell Sotto and Cultepe) was also characteristically dung-tempered, but had very high concentrations of organic temper (up to $70 \%$, mostly around $60 \%$ ). By the time of the archaic Hassuna, as seen in the lower layer (XII) at Yarim Tepe I, the concentration of dung organics in pottery had fallen below $40 \%$ and, as already noted, the transition to standard Hassuna was marked by a further reduction in concentrations to between 10 and 30\% (Fig. 4).

\section{The analysis of pottery surface treatment}

Potters used a variety of surface treatments and decoration such as smoothing, polishing, coating (with an additional layer of clay) and slipping as we observed in the pottery from Yarim Tepe I. The latter three types of surface treatment are considered separately in the discussion of vessel decoration techniques. Apart from the vessel bases, which were characterised only by coarse smoothing, the pottery surfaces from horizon XII were typically smoothed carefully. Moreover, the smoothing lines have a definite orientation in all cases, often running diagonally from the rim. In contrast, the vessels from horizon VII are mostly characterised by a more horizontal smoothing direction. Whether this suggests the development of pottery technology or the chan- 
ging preference of potters is a subject for future research.

\section{Analysis of pottery decoration techniques}

In addition to polishing and coating and the application of a slip as surface decoration, the use of ochre as a colorant, the use of plastic relief decoration and incisions are also worth mentioning (Fig. 5).

Red colour was added after firing on cups and jars in $55 \%$ of all vessels from horizon XII in the period of archaic Hassuna. The traces of a poorly preserved coarse coating (presumably of lighter clay) applied after firing either to one or both surfaces of the vessels was only rarely recorded (in $23 \%$ ). On some bowls and jars smoothing is supplemented by polishing of the dried surface (18\%). Plastic relief decoration was identified on only one vessel.

The pottery of the later horizon VII presents a different picture. Most of the pottery, except for basins, have traces of painting with red colour (ochre) applied before firing or painting with brown colour applied after firing. It is interesting to note that the brown colour, which is typical for bowls, was composed of non-local raw materials. This colorant was identified in only one jug of the 'local' pottery group. The brown paint on the pottery surface changed to red when re-fired in a muffle furnace at $850^{\circ} \mathrm{C}$ as was discovered in our analysis. Consequently, the colour differences noted on the pottery surfaces were not associated with the use of various mineral dyes, but reflect the fact that the brown colorant was applied after firing. A thin layer of light-coloured slip was identified on bowls and jars of local production in $31 \%$ of the vessels. It is important to emphasise that bowls, which were considered non-local, had no slip applied to their surface. Perhaps the technology of coating the pottery surface with a slip was the result of local traditions connected with the desire to improve the surface quality. Polishing and incisions were identified together on only one cup. The use of decorative incisions on bowls is also related to pro-

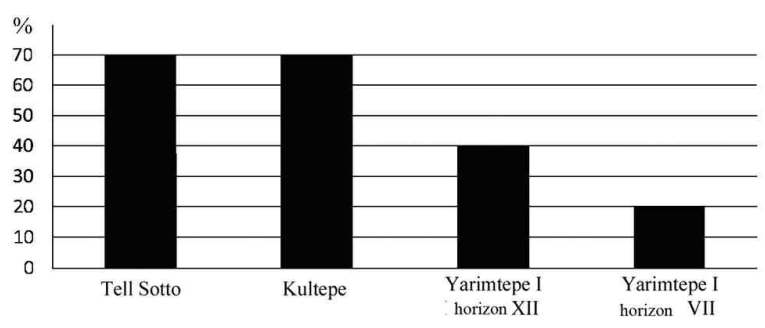

Fig. 4. The frequencies of the presence of dung in the pottery pastes from various Neolithic sites. ducts that, judging by their composition, were not made locally, which is particularly true for those with a weakly ferruginated clay body.

Thus, it may be noted that the transition from the archaic to the standard Hassuna period was again characterised by a significant change in the traditions of pottery decoration. The decoration techniques such as the use of brown, ochre paint and incisions, which in most cases were associated with 'nonlocal' fabrics, were of particular interest.

\section{The study of firing technology}

Due to our pottery analysis we can make some comments and observations about the conditions and the firing characteristics. The external and internal surfaces of most pottery are calcined, while the middle layer has a light grey or slightly reddish colour. The boundaries of transition between the firing horizons are often indistinct. Thinner pottery sherds are calcined throughout. The features observed suggest that the pottery was fired after a long soaking time, at temperatures above $650^{\circ} \mathrm{C}$ in an oxidising environment, and with slow cooling of the vessels within the firing structure (Bobrinsky 1999.96).

This information is consistent with the technical capacities of the furnaces found at the settlement. In horizons IX, VII and V the remains of small updraft pottery kilns with firing chambers approximately $0.7-1.25 \mathrm{~m}$ in diameter were discovered (Tsetlin 2004.412-413). It is probable that such kilns were used for firing smaller vessels.

These characteristics were typical of the vast majority of the assemblage; only two locally made vessels (one from each horizon) showed evidence of a different firing sequence. These vessels attested to a final stage of firing in reducing conditions, as they are grey in the centre with a darker, sharply defined horizon on both surfaces (varying in thickness from 0.1 to $1-2 \mathrm{~mm}$ ). Whether this was connected to any additional surface treatment could not be determined.

\section{Discussion}

The technological study of the Hassuna ceramics from Yarim Tepe I allows us to present some preliminary conclusions. On the whole, the general scheme of development of Hassuna culture - originally recorded at the eponymous site Tell Hassuna and further defined by excavations at Yarim Tepe I - was sup- 


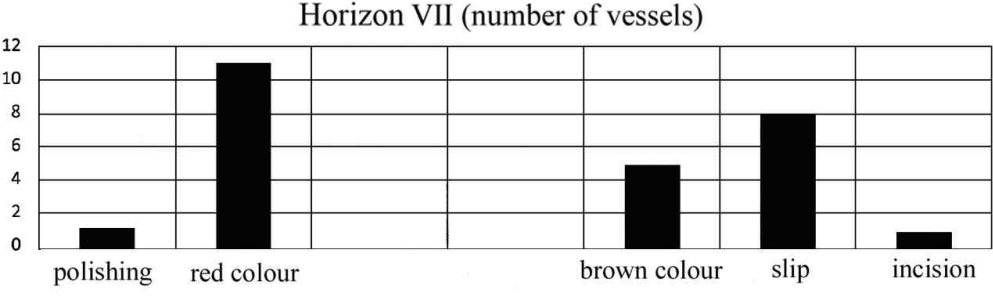

Horizon XII (number of vessels)

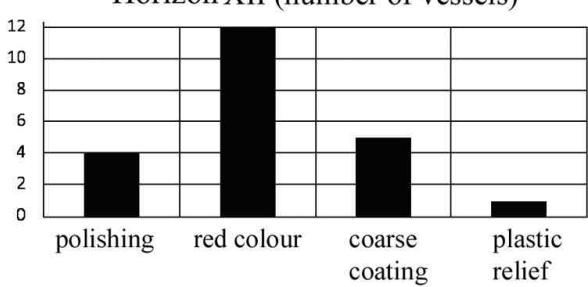

Fig. 5. Number of vessels according to decorating techniques from Yarim Tepe I, horizon VII and horizon XII.

had been used here in earlier periods. These products were decorated with brown paint and incisions and should probably be classified as a cultural import.

Thus, we can conclude that in the earliest period of settlement, the population was not uniform in their traditions. At least two systems of pottery technology can be identified in the various traditions of selecting and manipulating raw materials used for pottery production. One of these systems was clearly predominant and more archaic. It had its roots in this

ported. By comparing the pottery from different horizons (XII and VII) it has been possible to contribute further to our understanding of the process of transition from the archaic to the standard stage of Hassuna culture. Specifically, we discovered that within the archaic Hassuna horizon (XII) two pottery technologies were in use. The population of the first (most prevalent) system, which had its roots in the immediate locale, used three types of local clays with the addition of dung from small livestock in significant concentrations (about 20-40\%) in combination with coarser plant materials as temper. For pottery decorations red paint, clay plastered vessel surfaces, and polished and relief decorations were used. For the second system, considered to be nonlocal in origin, only one clay source (the first type) was used, which was also the main resource for pottery. Red ochre paint was used for decoration.

During the transition to standard Hassuna in horizon VII, the situation changed significantly. At this time, vessels made from non-local clay resources begin to appear that are connected to the second system of pottery technology, individual examples of which region and was already discussed by Bobrinsky during his study of the earlier sites at Tell Sotto and Kultepe (Bobrinsky 1989.27-334). The second system of pottery technology came to the settlement from the outside. A consideration of a number of technological factors suggests that there was a gradual process of synthesis of both traditions. This is seen particularly in the use of a mixture of two different clays and the gradual reduction in the concentration of dung temper in the paste, as well as in some of the methods of decoration. It must be noted that the results obtained here are still preliminary. We hope that a future studies of the large pottery collections from Yarim Tepe I will add further details and clarify these conclusions.

\section{ACKNOWLEDGEMENTS}

My deepest thanks go to Prof. Rauf M. Munchaev and Dr. Nikolai Ya. Merpert for providing access to the Yarim Tepe I materials for this study and publication, and to Dr. Alexander A. Bobrinsky, Dr. Yuri B. Tsetlin and Dr. Shahmardan N. Amirov for their advice and assistance with the analysis of the material.

\section{References}

Bobrinsky A. A. 1978. Pottery of the Eastern Europe. Sources and Methods of Study. Nauka Press. Moscow. (in Russian)

1981a. The secrets of the ancient potters. Science and lives 10: 76-77. (in Russian)

1981b. At the origin of pottery art. Nature 4: 118-119. (in Russian)
1989. Technological characteristics of ceramics from Tell Sotto and Kúltepe. In N. 0. Bader (ed.), The earliest agriculturalists in ancient Mesopotamia. Nauka Press, Moscow: 327-334. (in Russian)

1999. Pottery technology as an object of cultural-andhistorical study. In A. A. Bobrinsky (ed.), Actual Problems of Ancient Pottery Investigations. Samara State Pedagogical University Press, Samara: 5-109. (in Russian) 
Bobrinsky A. A., Vasilyeva I. N. 1998. On some peculiarities of plastic raw materials in the history of pottery production. In Problems of North Caspian basin history. State Pedagogical University Samara Press, Samara: 193217. (in Russian)

Elias S. 2003. Hassuna Culture of the Northern Mesopotamia. Unpublished PhD thesis. Lomonosov Moscow State University. Moscow. (in Russian)

Lloyd S., Safar F. 1945. Tell Hassuna: Excavations by the Iraq Government Directorate of Antiquities in 1943-1944. Journal of Near Eastern Studies 4(4): 255-330.

Lopatina 0. A., Kazdym A. A. 2010. The natural sand inclusions in ancient ceramics (the discussion of the issue). Ancient Pottery Production. Results and Prospects of Investigation. Institute of Archaeology, Moscow: 46-57. (in Russian)

Merpert N. Ya. 1993. The archaic phase of the Hassuna culture. In N. Yoffee, J. J. Clark (eds.), Early stages in the evolution of Mesopotamian civilization. Soviet excavations in Northern Iraq. The University of Arizona Press, Arizona: 115-127.

Munchaev R. M., Merpert N. Ya.1981. Earliest Agricultural Settlements of Northern Mesopotamia. Nauka Press. Moscow. (in Russian)

1993. Yarim Tepe I. In N. Yoffee, J. J. Clark (eds.), Early stages in the evolution of Mesopotamian civilization. Soviet excavations in Northern Iraq. The University of Arizona Press, Arizona: 73-114.
Petrova N. Y. 2011. Technological research of the Hassuna culture ceramics (by the materials of settlement Yarim Tepe I). Papers of the $3^{\text {rd }}$ (19th) All-Russia Archaeological Congress in Staraja Russa. Vol. II. Institute of History of Material Culture, Russian Academy of Sciences, St. Petersburg - Moscow - Novgorod: 398-399. (in Russian)

2012. Technological study of ceramics Hassuna culture of settlement Yarim Tepe I in Iraq. Rossiyskaja Archeologia 2: 15-22. (in Russian)

Tsetlin Y. B. 1993. The organic additives of animal origin in a clay dishes (to develop methods of study). Unpublished manuscript. Moscow. (in Russian)

1999. The main directions and approaches to the study of organic tempers in ancient ceramics. Actual problems of ancient pottery investigation. State Pedagogical University Samara Press. Samara: 110-140. (in Russian)

2003. Organic tempers in ancient ceramics. In S. Di Pierro, V. Serneels and M. Maggetti (eds.), Ceramic in the Society. Proceedings of the $6^{\text {th }}$ European Meeting on Ancient Ceramics. 3.-6. October 2001, Fribourg, Switzerland. Department of Geosciences, University of Fribourg, Fribourg: 289-310.

2004. Pottery Kiln at the Site Tell Hazna I in Syria. In R. M. Munchaev, N. Ya. Merpert and Sh. N. Amirov (eds.), Tell Hazna I. Religious and Administrative Center IV-III millennium BC in North-East Syria. Paleograph Press, Moscow: 404-424. (in Russian) 